\title{
Using observational data to inform the design of a prospective effectiveness study for a novel insulin delivery device
}

This article was published in the following Dove Press journal:

ClinicoEconomics and Outcomes Research

21 September 2013

Number of times this article has been viewed

\section{Michael Grabner \\ Yong Chen ${ }^{2}$ \\ Matthew Nguyen ${ }^{3}$ \\ Scott D Abbott ${ }^{3}$ \\ Ralph Quimbo'}

'HealthCore, Inc., Wilmington, DE, USA; ${ }^{2}$ Merck and Co., Inc., Whitehouse Station, NJ, USA;

${ }^{3}$ Valeritas, Inc., Bridgewater, NJ, USA

Correspondence: Michael Grabner HealthCore, Inc., 800 Delaware Avenue, Fifth Floor, Wilmington, DE I980I, USA Email mgrabner@healthcore.com
Objective: To inform the design and assess the feasibility of a prospective effectiveness study evaluating an insulin delivery device for patients with diabetes mellitus to be conducted within the membership of a large US commercial insurer.

Methods: Providers who issued $\geq 1$ insulin prescription between January 1, 2011 and September 30, 2011 were selected from administrative claims contained in the HealthCore Integrated Research Database ${ }^{\mathrm{SM}}$. Adult diabetes patients with visits to these providers were identified. Providers were dichotomized into high- (HVPs) and low-volume providers (LVPs) based on median number of diabetes patients per provider.

Results: We identified 15,349 HVPs and 15,313 LVPs (median number of patients =14). Most HVPs were located in the Midwest (6,291 [41.0\%]) and South (5,092 [33.2\%]), while LVPs were evenly distributed across regions. Over $80 \%(12,769)$ of HVPs practiced family or internal medicine; $6.4 \%$ (989) were endocrinologists. HVPs prescribed insulin to an average of $25 \%$ of patients. Patients of HVPs $(522,527)$ had similar characteristics as patients of LVPs $(80,669)$, except for geographical dispersion, which followed that of providers. Approximately $65 \%$ of patients were aged 21-64 years and 97\% had type 2 diabetes. Among patients with $\geq 1$ available $\mathrm{HbA}_{1 \mathrm{C}}$ result during $2011(103,992), 48.3 \%(50,193)$ had an average $\mathrm{HbA}_{1 \mathrm{C}} \geq 7.0 \%$. Among patients initiating insulin, $79.6 \%(22,205)$ had an average $\mathrm{HbA}_{1 \mathrm{C}} \geq 7.0 \%$.

Conclusion: The observed provider and patient populations support the feasibility of the prospective study. Sampling of patients from HVPs is efficient while minimizing bias as patient characteristics are similar to those from LVPs. The study also highlights unmet needs for improved glycemic control since approximately half of patients with diabetes are not on goal.

Keywords: diabetes mellitus, claims analysis, prospective study design, insulin delivery

\section{Background}

The American Diabetes Association (ADA) recommends a hemoglobin $\mathrm{A}_{1 \mathrm{c}}$ $\left(\mathrm{HbA}_{1 \mathrm{c}}\right)$ level below $7.0 \%$ as a goal for most patients diagnosed with diabetes mellitus. ${ }^{1}$ Achieving and maintaining glycemic goals leads to reduced morbidity and mortality over the long term, as well as reduced health care costs and resource utilization. ${ }^{2-7}$ Yet, the proportion of patients who maintain recommended glycemic levels is low and has consistently remained low. ${ }^{4,8-10}$ Data from the National Health and Nutrition Examination Survey showed that among people with diabetes, the mean $\mathrm{HbA}_{1 \mathrm{c}}$ level was $7.18 \%$ in 2003-2004. ${ }^{11}$ Although an improvement from the mean level of 7.82\% in 1999-2000, only $56.8 \%$ of the patients had $\mathrm{HbA}_{1 \mathrm{c}}$ levels below $7.0 \%$ in $2003-2004 .{ }^{11}$

Complex diabetic treatment regimens, the need for multiple medications, and patient resistance to insulin therapy are known to affect goal attainment. ${ }^{12-17}$ Reasons for resisting 
insulin therapy include fears of weight gain, hypoglycemia, and pain related to injections and testing, as well as embarrassment of having to inject insulin in public places. ${ }^{15-17}$ A survey of patients using insulin delivered either by syringe or pen revealed $23 \%$ of patients thought the insulin injections interfered with their daily activities more than a little, and 25\% believed injections negatively affected at least one of their normal daily activities. A full third of patients surveyed said they dreaded their injections. These perceptions lead to $57 \%$ of patients admitting they skipped necessary insulin doses, $20 \%$ of whom skipped needed doses sometimes or often. ${ }^{18}$ A 2011 survey of 2,104 patients ( 692 on insulin) found that $72 \%$ of patients who were on three or more injections per day did not take insulin away from home, while $96 \%$ of patients on 1-2 injections per day did not take injections away from home. ${ }^{19}$ In short, adherence to insulin therapy is directly influenced by the complexity of the regimen and the burden of treatment.

Therefore, there is a clear need for simplified insulin regimens that minimize patient concerns to help patients increase treatment adherence and reach treatment goals. Improved insulin delivery devices help address patient concerns about injections while simplifying insulin administration. The V-Go ${ }^{\circledR}$ Disposable Insulin Delivery Device (Valeritas, Inc., Bridgewater, NJ, USA) allows for continuous subcutaneous delivery of a basal rate of insulin over a 24-hour period with on-demand bolus dosing at mealtimes, eliminating the need for multiple injections throughout the day. The device is mechanical, not electronic, providing convenient and simple physiologic basal bolus delivery of insulin. The efficacy of the device has been previously demonstrated in small-scale settings, ${ }^{15,20}$ however, prospective real-world effectiveness data are limited.

To inform the design of such a prospective real-world study, a retrospective administrative claims analysis was conducted. While study design is often informed by a systematic literature review, the statistics from such a review may not be directly applicable to a prospective study. A retrospective analysis of the target population was thought to be more informative. The objectives of the retrospective claims analysis were twofold: (1) to describe the characteristics of the providers who prescribe insulin for patients with diabetes mellitus within the population of a large commercial health insurer; and (2) to provide a foundation for the methods of a prospective study of the V-Go Disposable Insulin Delivery Device, including a feasibility assessment and strategies to identify suitable provider sites and patient populations. This study may also serve as a model to shape the design of prospective studies in other areas, whenever information on the patient and/or provider population of interest is available at the outset.

\section{Research design and methods}

This retrospective cross-sectional analysis used data compiled from the HealthCore Integrated Research Database (HIRD ${ }^{\mathrm{SM}}$ ). The HIRD ${ }^{\mathrm{SM}}$ is an integrated medical and pharmacy claims dataset of commercially insured patients. The database includes claims data for 14 major commercial health plans across the US representing 44 million lives. The database captures patients' medical claims, pharmacy claims, and laboratory tests, as well as provider characteristics. All data were handled in compliance with the Health Insurance Portability and Accountability Act of 1996. Institutional review board approval was not required since researchers only had access to a limited study database with masked patient identifiers.

\section{Provider identification}

Providers who prescribed insulin (generic product identifier [GPI] 2710x) at least once during the study period (January 1, 2011 through September 30, 2011) were identified from pharmacy claims and stratified according to patient volume. Patient volume per provider was determined by the annual number of patients with diabetes (International Classification of Diseases-ninth revision, Clinical Modification [ICD-9-CM]: 250.xx) seen by each provider. Using the number of patients per provider, providers were divided into two groups: high-volume providers (HVPs), which were those who had a patient volume equal to or higher than the median; and low-volume providers (LVPs), or those with a patient volume below the median.

\section{Patient identification}

All patients in the study had a diagnosis of type 1 or type 2 diabetes, were 21 years of age or older, and had seen a provider previously identified by pharmacy claims. Patients were required to have available medical and pharmacy administrative claims as well as continuous and currently active health plan eligibility during the 2011 calendar year. Laboratory results were available for part of the population. Patients were stratified by the patient volume of their prescribing physician (high or low) during 2011. Note that a single patient may have seen multiple providers.

\section{Outcome measures}

Provider characteristics included geographic region of provider practice, specialty, the average number of patients per provider with type 1 or type 2 diabetes, frequency of insulin prescriptions, and number of currently active patients per provider. Among patients with available electronic laboratory results for $\mathrm{HbA}_{1 \mathrm{c}}$, the average prevalence per provider of 
patients with $\mathrm{HbA}_{1 \mathrm{c}}$ levels $\geq 7.0 \%$ during the study period was also evaluated. Provider prescribing patterns were measured by the average prevalence of patients without any antidiabetic prescription fills, oral antidiabetic agents (including sulfonylureas [GPI: 2720x], antidiabetic amino-acid derivatives [GPI: 2723x], metformin [GPI: 2725x], meglitinides [GPI: 2728x], alpha-glucosidase inhibitors [GPI: 2750x], dipeptidyl peptidase-4 inhibitor [GPI: 2744x], insulin sensitizing agents [GPI: 2780x] [ie, thiazolidinediones], or any combination thereof [GPI: 2799x]), or insulin (either basal, premix, regular, fast-acting, or any combination). Glycemic control was measured as the proportion of patients with average $\mathrm{HbA}_{1 \mathrm{c}}$ levels above the ADA recommended goal of $7.0 \%$, as determined by laboratory results.

For patients, outcome measures included demographic characteristics, geographic region, and comorbid conditions, which were identified using ICD-9-CM diagnosis and procedure codes.

\section{Statistical analysis}

Descriptive statistics including means and standard deviations were used for continuous data; relative frequencies and proportions were used for categorical data. Due to the exploratory nature of this study, no hypothesis testing was performed.

\section{Results}

\section{Provider and patient characteristics}

A total of 30,662 providers were identified from claims as having at least one insulin prescription during 2011

Table I Provider and patient identification

\begin{tabular}{|c|c|}
\hline Provider identification & $\begin{array}{l}\text { Number } \\
\text { of providers (\%) }\end{array}$ \\
\hline $\begin{array}{l}\text { Providers with } \geq I \text { insulin prescription } \\
\text { between January I, 20I I and September 30, 20II, } \\
\text { with patients }>=2 \mathrm{I} \text { years of age }\end{array}$ & $30,662(100 \%)$ \\
\hline HVPs & $15,349(50.1 \%)$ \\
\hline LVPs & $15,313(49.9 \%)$ \\
\hline Patient identification & $\begin{array}{l}\text { Number } \\
\text { of patients (\%) }\end{array}$ \\
\hline $\begin{array}{l}\text { Patients }>=2 \mathrm{I} \text { years of age with a diagnosis of } \\
\text { diabetes seen by the selected providers, with } \\
\text { continuous health plan eligibility between } \\
\text { January I, } 201 \mathrm{I} \text { and September } 30,20 \mathrm{II}\end{array}$ & $603,196(100 \%)$ \\
\hline Patients seen by an HVP & $522,527(86.6 \%)$ \\
\hline Patients seen by an LVP & $80,669(13.4 \%)$ \\
\hline
\end{tabular}

Note: ${ }^{2}$ These are nonunique patient counts, since a given patient could have visits to multiple providers.

Abbreviations: HVP, high-volume provider; LVP, low-volume provider.
(Table 1). The median number of patients per provider was 14 . Among all providers, 15,349 had 14 or more patients and were classified as HVPs in 2011; 15,313 providers were classified as LVPs.

On average, each HVP saw 34 patients with diabetes as compared to five patients with diabetes for an LVP in 2011. HVPs were located mostly in the Midwest (6,291 providers, $41.0 \%)$ and South (5,092 providers, $33.2 \%)$ versus the Northeast $(1,859$ providers, $12.1 \%)$ and West $(2,107$ providers, $13.7 \%$ ). LVPs were more evenly dispersed geographically (Table 2). A total of 489 providers were identified in the database who had at least 25 patients who met the minimum criteria for the prospective study (type 2 diabetes, $\geq 1$ insulin

Table 2 Provider characteristics stratified by provider volume in 2011

\begin{tabular}{|c|c|c|}
\hline \multirow[t]{2}{*}{ Provider characteristics } & \multirow{2}{*}{$\frac{\text { High volume }^{a}}{n=15,349}$} & \multirow{2}{*}{$\frac{\text { Low volume }}{n=15,313}$} \\
\hline & & \\
\hline \multicolumn{3}{|l|}{ Demographics } \\
\hline \multicolumn{3}{|l|}{ Region, n (\%) } \\
\hline Northeast & $1,859(12.1)$ & $3,493(22.8)$ \\
\hline Midwest & $6,291(41.0)$ & $4,123(26.9)$ \\
\hline South & $5,092(33.2)$ & $3,923(25.6)$ \\
\hline West & $2,107(13.7)$ & $3,774(24.7)$ \\
\hline \multicolumn{3}{|l|}{ Specialty, n (\%) } \\
\hline Primary-care physician & $6,939(45.2)$ & $4,87 \mid(3 \mid .8)$ \\
\hline Endocrinologist & $989(6.4)$ & $648(4.2)$ \\
\hline Internal medicine & $5,830(38.0)$ & $4,965(32.4)$ \\
\hline Other & $1,591(10.4)$ & $4,829(31.5)$ \\
\hline \multicolumn{3}{|l|}{ Patient density, mean n (mean \%) } \\
\hline \multicolumn{3}{|l|}{ Volume of patients (per provider) } \\
\hline Number of patients per provider & 34.04 & 5.27 \\
\hline Type I diabetes & $1.01(2.6)$ & $0.2(4.9)$ \\
\hline Type 2 diabetes & $33.03(97.4)$ & $5.07(95.1)$ \\
\hline \multicolumn{3}{|c|}{ Prescribing patterns, mean n (mean \%) } \\
\hline \multicolumn{3}{|l|}{ Antidiabetic treatments (per provider) } \\
\hline No prescription fills & $9.28(27.9)$ & $1.27(19.0)$ \\
\hline Oral antidiabetics & $20.25(60.0)$ & $3.09(57.1)$ \\
\hline Sulfonylureas & $7.72(22.7)$ & I. $17(2 \mathrm{I} .4)$ \\
\hline Metformin & I3.38 (39.9) & $2.1(38.8)$ \\
\hline Meglitinides & $0.43(1.3)$ & $0.08(1.6)$ \\
\hline $\begin{array}{l}\text { Alpha-glucosidase } \\
\text { inhibitors }\end{array}$ & $0.1(0.3)$ & $0.02(0.4)$ \\
\hline $\begin{array}{l}\text { Dipeptidyl peptidase- } 4 \\
\text { inhibitors }\end{array}$ & $3.17(9.3)$ & $0.48(8.7)$ \\
\hline Insulin sensitizing agents & $3.22(9.5)$ & $0.49(9.3)$ \\
\hline Antidiabetic combinations & $3.12(9.0)$ & $0.43(8.1)$ \\
\hline Insulin & $8.95(24.9)$ & $1.84(48.3)$ \\
\hline Basal only & $2.81(8.3)$ & $0.59(15.6)$ \\
\hline Premix only & $0.8(2.3)$ & $0.15(3.8)$ \\
\hline Regular only & $0.12(0.3)$ & $0.02(0.5)$ \\
\hline Fast-acting only & $1.27(3.1)$ & $0.21(5.1)$ \\
\hline Any insulin combination & $3.95(11.0)$ & $0.87(23.3)$ \\
\hline Pen & $5(13.9)$ & I.0I (26.8) \\
\hline
\end{tabular}

Note: "“High-volume providers" are those with $\geq 14$ diabetic patients in $201 \mathrm{I}$. 
prescription, aged 21 or older). Most providers were primary care or internal medicine physicians with only a minority specializing in endocrinology. HVPs had a higher proportion of primary care and internal medicine physicians and endocrinologists compared with LVPs (Table 2).

\section{Treatment patterns}

A greater proportion of patients seen by HVPs received no antidiabetic prescription fills compared with patients seeing LVPs (27.9\% versus 19.0\%, respectively). On average, approximately $58.5 \%$ of patients seen by HVPs and LVPs were prescribed oral antidiabetic agents in 2011. The most commonly prescribed oral agent was metformin, prescribed to approximately $39.4 \%$ of patients of both HVPs and LVPs (Table 2).

The average proportion of patients who received insulin was higher among LVPs than HVPs (48.3\% versus $24.9 \%$, respectively; Table 2). By specialty, endocrinologists prescribed more insulin (52.5\%) and fewer oral agents (54.5\%) compared with primary care (insulin, $22.0 \%$; oral agents, $62.0 \%$ ) and internal medicine physicians (insulin, 24.9\%; oral agents, 58.3\%; data not shown).

\section{Patient characteristics}

In 2011, 30,662 providers identified from the pharmacy claims as having $\geq 1$ insulin prescription during the study period saw a total of 603,196 patients with diabetes aged 21 years or older. One patient could see multiple providers in a year (the unique patient count was 325,311). Nearly half of the patients were women, $96.9 \%$ had type 2 diabetes, and two-thirds were aged 21-64 years. Most patient characteristics were similar regardless of whether patients saw an HVP or LVP (Table 3). Geographical distribution was the only patient characteristic that varied between patients of HVPs versus LVPs. The majority of HVP patients resided in the Midwest (215,647 patients, $41.3 \%)$ or South (169,002 patients, $32.3 \%$ ), while LVP patients were more evenly distributed across regions, similar to the provider distribution (Table 3).

\section{Glycemic control}

Electronic $\mathrm{HbA}_{1 \mathrm{c}}$ laboratory results were available for $17.1 \%$ and $13.0 \%$ of patients visiting HVPs and LVPs, respectively, for a total of 103,992 patients (the unique patient count with electronic $\mathrm{HbA}_{1 \mathrm{c}}$ laboratory results was 55,389, equivalent to $17.0 \%$ of the total number of unique patients in the study). Of the 103,992 patients who had a laboratory test for $\mathrm{HbA}_{1 \mathrm{c}}, 48.3 \%$ (50,193 patients) had an average $\mathrm{HbA}_{1 \mathrm{c}}$ level above the ADA-
Table 3 Patient characteristics stratified by provider volume in 2011

\begin{tabular}{|c|c|c|}
\hline Patient characteristics & $\begin{array}{l}\text { High-volume } \\
\text { providers }^{a}\end{array}$ & $\begin{array}{l}\text { Low-volume } \\
\text { providers }\end{array}$ \\
\hline Number of patients & 522,527 & 80,669 \\
\hline \multicolumn{3}{|l|}{ Demographics, n (\%) } \\
\hline Age (years), mean $( \pm S D)$ & $60.4(13.6)$ & $59.11(14.2)$ \\
\hline $21-64$ & $339,447(65.0)$ & $54,490(67.6)$ \\
\hline$\geq 65$ & $183,080(35.0)$ & $26,179(32.5)$ \\
\hline Female & $263,485(50.4)$ & $39,505(49.0)$ \\
\hline \multicolumn{3}{|l|}{ Health plan type } \\
\hline HMO & I34,444 (25.7) & $|0,75|(\mid 3.3)$ \\
\hline POS & $8,359(1.6)$ & $2,210(2.7)$ \\
\hline PPO & $310,960(59.5)$ & $53,170(65.9)$ \\
\hline Other & $64,472(12.3)$ & $13,210(16.4)$ \\
\hline \multicolumn{3}{|l|}{ Region } \\
\hline Northeast & $52,552(10.1)$ & $15,710(19.5)$ \\
\hline Midwest & $215,647(4 \mid .3)$ & $23,297(28.9)$ \\
\hline South & $169,002(32.3)$ & $|4,75|(\mid 8.3)$ \\
\hline West & $57,606(11.0)$ & $22,766(28.2)$ \\
\hline Unknown & $27,720(5.3)$ & $4,145(5.1)$ \\
\hline \multicolumn{3}{|l|}{ Medicare prescription drug plan } \\
\hline Any Medicare & | 46,205 (28.0) & $19,876(24.6)$ \\
\hline Advantage & $107,277(20.5)$ & $12, \mid 40(\mid 5.1)$ \\
\hline Supplemental & $32,930(6.3)$ & $6,209(7.7)$ \\
\hline Part D & $24,225(4.6)$ & $6,073(7.5)$ \\
\hline \multicolumn{3}{|l|}{ Medical history } \\
\hline \multicolumn{3}{|l|}{ Disease of interest } \\
\hline Type I diabetes & $15,578(3.0)$ & $2,999(3.7)$ \\
\hline Type 2 diabetes & $506,949(97.0)$ & $77,670(96.3)$ \\
\hline \multicolumn{3}{|l|}{ Comorbidities } \\
\hline Hypertension & $381,037(72.9)$ & $53,931(66.9)$ \\
\hline Hyperlipidemia & $352,307(67.4)$ & $47,404(58.8)$ \\
\hline Neuropathy & $62,857(12.0)$ & $10,319(12.8)$ \\
\hline Retinopathy & $56,083(10.7)$ & $9,042(11.2)$ \\
\hline Obesity & $56,335(10.8)$ & $9,195(11.4)$ \\
\hline Mental illness & I I 2,286 (2I.5) & I7,I67 (21.3) \\
\hline Severe mental illness & $35,207(6.7)$ & $5,900(7.3)$ \\
\hline $\begin{array}{l}\text { Other ischemic heart disease } \\
\text { and angina }\end{array}$ & I03,46| (19.8) & 15,377 (19.1) \\
\hline Amputation and ulceration & $20,695(4.0)$ & $3,759(4.7)$ \\
\hline $\begin{array}{l}\text { Quan-Charlson }{ }^{21} \text { comorbidity } \\
\text { index (mean } \pm S D)\end{array}$ & I.4| (2.0) & $1.52(2.1)$ \\
\hline
\end{tabular}

Note: "'High-volume providers" are those with $\geq 14$ diabetic patients in $201 \mathrm{l}$. Abbreviations: HMO, health maintenance organization; POS, point of service; PPO, preferred provider organization; SD, standard deviation.

recommended goal of $<7 \%$ during 2011. Among patients with an average $\mathrm{HbA}_{1 \mathrm{c}}<7.0 \%, 10.6 \%$ received insulin, compared with $44.2 \%$ who had $\mathrm{HbA}_{\mathrm{lc}}$ levels $\geq 7.0 \%$. Additionally, $59.6 \%$ of those with average $\mathrm{HbA}_{1 \mathrm{c}}$ levels $<7.0 \%$ received oral antidiabetic medications, compared with $71.6 \%$ of those who had $\mathrm{HbA}_{1 \mathrm{c}}$ levels $\geq 7.0 \%$. Approximately a third of patients (35.1\%) with $\mathrm{HbA}_{1 \mathrm{c}}$ levels $<7.0 \%$ received no antidiabetic prescription fills compared with $8.8 \%$ of patients who had $\mathrm{HbA}_{\mathrm{lc}}$ levels $\geq 7.0 \%$ (Table S1). 
The mean $\mathrm{HbA}_{1 \mathrm{c}}$ level among all patients with at least one $\mathrm{HbA}_{1 \mathrm{c}}$ laboratory result was $7.4 \%( \pm 1.7 \%)$, with $51.7 \%$ of patients at the ADA-recommended level. Mean $\mathrm{HbA}_{1 \mathrm{c}}$ levels were similar between patients of HVPs and LVPs (7.4\% and $7.5 \%$, respectively), with similar percentages of patients at recommended levels (51.8\% for HVPs and 50.8\% for LVPs; Table 4). Among patients receiving insulin, however, the mean $\mathrm{HbA}_{1 \mathrm{c}}$ level was $8.5 \%( \pm 1.9 \%)$, and only $20.4 \%$ of these patients were at the recommended level. Results were very similar across primary care, internal medicine, and other medical provider groups; these providers were, therefore, grouped together as "Other" for the purposes of evaluation (Table 4). Endocrinologists as a subspecialty had a higher percentage of patients above the recommended $\mathrm{HbA}_{1 \mathrm{c}}$ level of $<7.0 \%$, likely reflecting the increased complexity and severity of diabetes in this patient population.

\section{Discussion}

The diabetes treatment patterns observed among insulin prescribing providers identified in the HIRD ${ }^{\mathrm{SM}}$ were close to national averages; for example, the low use of thiazolidinediones follows national trends (data not shown). ${ }^{12}$ On the other hand, the use of metformin in our provider sample is lower than the 2007 national average of 54\%. ${ }^{12}$ This may be due to a variety of reasons: introduction of newer antidiabetic treatments since 2007; patterns of current diabetes management within the confines of our study population; and maybe also an implication of our study design, which selected providers who prescribed insulin, such that overall metformin use within this provider population is underrepresented. Our analysis also showed that providers who treat a high volume of patients with diabetes had a greater prevalence of patients receiving no antidiabetic prescription medications compared with LVPs. One possible explanation may be that HVPs are more likely to have the resources to recommend and supervise changes to health behaviors to their patients, such as diet modification and exercise, which are not captured in the claims. It is also possible that HVPs may have a higher proportion of patients who cannot afford medications and try alternative measures.

The findings regarding glycemic control also reflect national trends that have been described in previous studies. ${ }^{4,8-11}$ A longitudinal, national health survey of people with diabetes found mean $\mathrm{HbA}_{1 \mathrm{c}}$ levels of 7.18\% in 2003-2004, and only $56.8 \%$ of patients had $\mathrm{HbA}_{1 \mathrm{c}}$ levels below $7.0 \%{ }^{11}$ In the current analysis of patients with diabetes enrolled in large commercial health plans, half of those with electronic laboratory results had an average $\mathrm{HbA}_{1 \mathrm{c}}$ level $\geq 7.0 \%$ in 2011 , which exceeds the level recommended by the ADA for most patients with diabetes. Among patients taking insulin, the mean $\mathrm{HbA}_{1 \mathrm{c}}$ level was $8.5 \%$, with $79.6 \%$ of patients having levels $\geq 7.0 \%$. This finding is also consistent with previously published studies, which demonstrated that among patients taking insulin, approximately $60 \%$ have levels exceeding the recommended $7.0 \% .{ }^{22-24}$ Furthermore, despite a provider analysis population selected based on the presence of insulin prescriptions, $55.8 \%$ of patients who had an average $\mathrm{HbA}_{1 \mathrm{c}}$ level $\geq 7.0 \%$ were not receiving insulin.

Despite these trends for glycemic control, insulin remains a readily available and effective treatment for uncontrolled diabetes. Adherence to insulin, however, is low. ${ }^{17}$ Patients resist insulin therapy because of inconvenience, embarrassment related to injections, and pain. ${ }^{15-17}$ Injections are hard to keep private with traditional insulin delivery devices; the "fear of embarrassment in public" is the second most important reason why patients did not take insulin therapy. ${ }^{15}$ Alternative delivery options are becoming available that may increase adherence. Delivering insulin to mimic normal physiology through a more convenient device may help reduce $\mathrm{HbA}_{1 \mathrm{c}}$ levels to within recommended ranges. ${ }^{1,15,20}$ The results of this retrospective analysis showed that among patients with at least one laboratory test for $\mathrm{HbA}_{1 \mathrm{c}}$, half had glycemic levels above the recommended goal. Moreover, nearly $80 \%$ of patients who received insulin therapy in 2011 had an $\mathrm{HbA}_{1 \mathrm{c}}$

Table $4 \mathrm{HbA}_{\mathrm{Ic}}$ distribution among patients with diabetes

\begin{tabular}{|c|c|c|c|c|c|c|}
\hline & \multirow[t]{2}{*}{ All patients } & \multirow{2}{*}{$\begin{array}{l}\text { Patients with } \\
\text { insulin }^{\mathrm{a}}\end{array}$} & \multicolumn{2}{|c|}{ Provider specialty } & \multirow{2}{*}{$\begin{array}{l}\text { High-volume } \\
\text { providers }^{\text {b }}\end{array}$} & \multirow{2}{*}{$\begin{array}{l}\text { Low-volume } \\
\text { Providers }\end{array}$} \\
\hline & & & Endo & Other & & \\
\hline Total patients, $\mathrm{n}$ & 103,992 & 27,897 & 11,349 & 92,643 & 92,164 & 11,828 \\
\hline Mean $\mathrm{HbA}_{\mathrm{Ic}} \%(\mathrm{SD})$ & $7.4 \mathrm{I}(1.7)$ & 8.49 (1.9) & $7.73(1.8)$ & 7.37 (I.7) & $7.40(1.7)$ & $7.45(1.7)$ \\
\hline Median $\mathrm{HbA}_{\mathrm{Ic}} \%$ & 6.9 & 8.1 & 7.3 & 6.9 & 6.9 & 6.9 \\
\hline$<7 \%$ & $53,799(51.7)$ & $5,692(20.4)$ & $4,579(40.4)$ & $49,220(53.1)$ & $47,786(51.9)$ & $6,013(50.8)$ \\
\hline$\geq 7 \%$ and $<8 \%$ & $22,572(21.7)$ & $7,379(26.5)$ & $2,817(24.8)$ & $19,756(21.3)$ & $20,054(21.8)$ & $2,519(21.3)$ \\
\hline$\geq 8 \%$ and $<9 \%$ & II,704 (I I.3) & $5,700(20.4)$ & I,699 (15.0) & $10,005(10.8)$ & $|0,33|(|| .2)$ & I,373 (II.6) \\
\hline$\geq 9 \%$ & $15,916(15.3)$ & $9,126(32.7)$ & $2,254(19.9)$ & I3,662 (14.8) & 13,993 (I5.2) & $1,923(16.3)$ \\
\hline
\end{tabular}

Note: aPatients with at least one fill for any insulin in 20II. "'High-volume providers" are those with $>=14$ diabetic patients in $201 \mathrm{I}$.

Abbreviations: Endo, endocrinologist; $\mathrm{Hb}_{\mathrm{Ic}}$, hemoglobin $\mathrm{A}_{\mathrm{Ic}}$; $\mathrm{SD}$, standard deviation. 
level above $7.0 \%$. This suggests a sizable population with unmet therapeutic needs who may be candidates for simpler and physiologic insulin therapy.

Strategies that delay or prevent $\mathrm{HbA}_{1 \mathrm{c}}$ levels from exceeding the recommended ranges, such as lifestyle management and metformin, are preferable to initiating insulin therapy after the fact. Diabetes-related costs begin accruing as early as 8 years before diabetes is diagnosed. ${ }^{25}$ Lifestyle modification, including weight loss and exercise, and the use of metformin are not only cost-effective preventive strategies but they are also cost-saving over the long term. ${ }^{26-28}$ Additionally, initiating oral antidiabetics or indeed insulin therapy early, perhaps even before diabetes is diagnosed, may reduce the incidence of diabetes and was cost effective for patients with cardiovascular risk factors and dysglycemia. ${ }^{29}$ Nevertheless, the progressive nature of diabetes typically requires intensification of therapy to achieve glycemic control, often involving insulin. ${ }^{1}$

The V-GoAL prospective study is currently underway to examine the effectiveness of the V-Go Disposable Insulin Delivery Device in improving insulin adherence and glycemic control compared with usual care. Results from this prospective study may then be linked with claims data to generate cost-effectiveness or cost-benefit analyses of using an insulin delivery device to improve glycemic control. The results of the retrospective claims analysis study reported here can be used to inform the prospective study and improve its design. The feasibility of using the HIRD ${ }^{\mathrm{SM}}$ to obtain study participants has been confirmed, as a sufficient number of providers were identified in the database who had at least 25 patients with diabetes who met the inclusion criteria for the prospective study. The retrospective claims results also indicated that providers who treated more than the median number of patients with diabetes were representative of all providers, with characteristics similar to those who treated fewer patients with diabetes. Thus, selecting providers who treat a high number of patients with diabetes to participate in the prospective study can be regarded as an efficient recruitment strategy to facilitate enrollment. The knowledge gained regarding the characteristics of the provider and patient populations contained in the HIRD ${ }^{\mathrm{SM}}$ may help avert bias in provider and patient selection. The approach outlined in this article may also serve as a model for future studies that seek to inform prospective research.

The results of the retrospective analysis have been used to inform the design of the prospective study, particularly in regard to selection of providers stratified by geographic region. The analysis showed a higher proportion of HVPs located in the Midwest and South, whereas LVPs were more evenly distributed geographically (Figure 1). The geographic distribution of providers, particularly HVPs, and patients reflects the national distribution of patients in this large commercial health plan and hence in the HIRD ${ }^{\mathrm{SM}}$. While it is reasonable that HVPs would more likely be concentrated in regions with higher densities of patients, LVPs would not necessarily need to be based in areas with greater numbers of patients with diabetes. Nevertheless, the geographic distribution of HVPs in the Midwest and South may lead

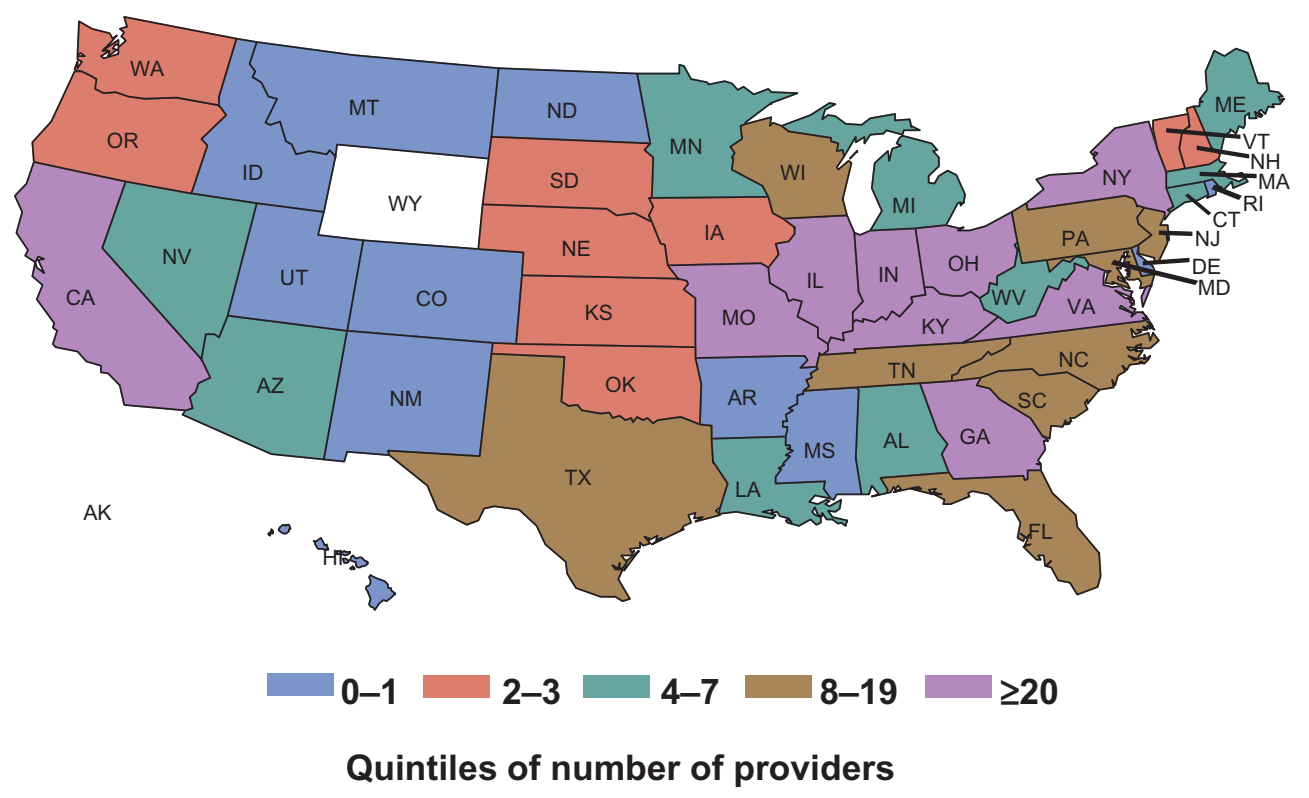

Figure I Distribution of providers with $\geq 25$ currently active diabetes patients across the US in 201 I. 
to oversampling of these two regions. Therefore, to have a nationally representative sample of providers, the prospective study will include randomly selected providers stratified by region.

\section{Limitations}

This analysis had some limitations. First, mean $\mathrm{HbA}_{1 \mathrm{c}}$ levels in 2011 were used to assess goal attainment; it is possible that patients had additional laboratory results not captured in the dataset and therefore may have been misclassified. Second, electronic $\mathrm{HbA}_{1 \mathrm{c}}$ laboratory results were available for a subset of approximately $15 \%$ of the total patient population; still, this represented more than 100,000 patients who were included in the evaluation of glycemic control. The percentages were representative of the overall study population and agreed with those reported in previous research. ${ }^{30}$

Third, the analysis assessed goal attainment at the population level, not taking account of individual patient circumstances, and did not examine patient adherence to therapy. To suit the design requirement for the prospective study, the providers selected for inclusion in this analysis were those with $\geq 1$ insulin prescription, thus the results may not generalize to providers who prescribe only oral antidiabetic agents. The claims data offered limited ability to examine provider characteristics (eg, age and years of practice) that may also affect treatment decisions. Lastly, claims-based research depends on the diagnostic and procedural codes entered onto forms, and coding errors may have occurred. Although the patient population was large, it was limited to those who are members of a large US commercial health plan, and the results may not be generalizable to those with different types of health insurance coverage or those in countries other than the US.

\section{Conclusion}

Using data from a large commercially insured population, this retrospective observational study investigated the characteristics of diabetic patients and their providers to help inform the design and feasibility of a prospective study of a new insulin delivery device. Patient characteristics were similar regardless of whether patients were treated by providers who had a high or low volume of patients with diabetes in their practices. Therefore, recruiting patients from practices of HVPs is an efficient strategy to facilitate enrollment into the prospective real-world study, without introducing bias. Selecting providers stratified by region may increase the national representativeness of the prospective study. Lastly, with as many as half of patients with diabetes, and nearly $80 \%$ of patients receiving insulin, having $\mathrm{HbA}_{1 \mathrm{c}}$ levels $\geq 7.0 \%$, there is clearly an unmet need for simplified insulin therapy.

\section{Acknowledgments}

M Grabner contributed to the study design, data analysis and interpretation, and manuscript development. Y Chen contributed to the study design, data analysis and interpretation, and manuscript development. M Nguyen contributed to the study design, interpreted data, and contributed to manuscript development. SD Abbott interpreted data and contributed to manuscript development. R Quimbo contributed to the study design, data interpretation, and manuscript development. All authors reviewed and approved the final draft of the manuscript. All authors had full access to the data. M Grabner takes responsibility for the integrity of the data and the accuracy of the data analysis.

The authors acknowledge Cheryl Jones, an employee of HealthCore, Inc., for editorial assistance in preparing the manuscript.

\section{Funding source}

Funding for the study was provided by Valeritas, Inc.

\section{Disclosure}

M Grabner and R Quimbo are employees of HealthCore, Inc., an independent research organization that received funding from Valeritas, Inc., to conduct the study. Y Chen, who was an employee of HealthCore, Inc., at the time the study was conducted, is an employee of Merck \& Co., Inc. M Nguyen and SD Abbott are employees of Valeritas, Inc. Authors declare no other conflicts of interest in this work.

\section{References}

1. American Diabetes Association. Standards of medical care in diabetes - 2012. Diabetes Care. 2012;35 Suppl 1:S11-S63.

2. Brown JB, Nichols GA. Case-control study of 10 years of comprehensive diabetes care. West $J$ Med. 2000;172(2):85-90.

3. CDC Diabetes Cost-Effectiveness Group. Cost-effectiveness of intensive glycemic control, intensified hypertension control, and serum cholesterol level reduction for type 2 diabetes. JAMA. 2002;287(19):2542-2551.

4. Dodd AH, Colby MS, Boye KS, Fahlman C, Kim S, Briefel RR. Treatment approach and $\mathrm{HbA}_{1 \mathrm{c}}$ control among US adults with type 2 diabetes: NHANES 1999-2004. Curr Med Res Opin. 2009;25(7):1605-1613.

5. Vouri SM, Shaw RF, Waterbury NV, Egge JA, Alexander B. Prevalence of achievement of A1c, blood pressure, and cholesterol (ABC) goal in veterans with diabetes. J Manag Care Pharm. 2011;17(4):304-312.

6. Menzin J, Korn JR, Cohen J, et al. Relationship between glycemic control and diabetes-related hospital costs in patients with type 1 or type 2 diabetes mellitus. J Manag Care Pharm. 2010;16(4):264-275.

7. Shetty S, Secnik K, Oglesby AK. Relationship of glycemic control to total diabetes-related costs for managed care health plan members with type 2 diabetes. J Manag Care Pharm. 2005;11(7):559-564. 
8. Berlowitz DR, Ash AS, Glickman M, et al. Developing a quality measure for clinical inertia in diabetes care. Health Serv Res. 2005;40(6 Pt 1): 1836-1853.

9. Blak BT, Smith HT, Hards M, Curtis BH, Ivanyi T. Optimization of insulin therapy in patients with type 2 diabetes mellitus: beyond basal insulin. Diabetic Med. 2012;29(7):e13-e20.

10. Gill JM, Foy AJ, Ling Y. Quality of outpatient care for diabetes mellitus in a national electronic health record network. Am J Med Qual. 2006;21(1):13-17.

11. Hoerger TJ, Segel JE, Gregg EW, Saadine JB. Is glycemic control improving in US adults? Diabetes Care. 2008;31(1):81-86.

12. Alexander GC, Sehgal NL, Moloney RM, Stafford RS. National trends in treatment of type 2 diabetes mellitus, 1994-2007. Arch Intern Med. 2008;168(19):2088-2094.

13. Huang ES, Basu A, Finch M, Frytak J, Manning W. The complexity of medication regimens and test ordering for patients with diabetes from 1995 to 2003. Curr Med Res Opin. 2007;23(6):1423-1430.

14. Rubin RR. Adherence to pharmacologic therapy in patients with type 2 diabetes mellitus. Am J Med. 2005;118(5A):27S-34S.

15. Kapitza C, Fein S, Heinemann L, Schleusener D, Levesque S, Strange P. Basal-prandial insulin delivery in type 2 diabetes mellitus via the $\mathrm{V}-\mathrm{Go}^{\mathrm{TM}}$ : a novel continuous subcutaneous infusion device. J Diabetes Sci Technol. 2008;2(1):40-46.

16. Petrak F, Stridde E, Leverkus F, Crispin AA, Forst T, Pfützner A. Development and validation of a new measure to evaluate psychological resistance to insulin treatment. Diabetes Care. 2007;30(9): 2199-2204.

17. Ross SA, Tildesley HD, Ashkenas J. Barriers to effective insulin treatment: the persistemce of poor glycemic control in type 2 diabetes. Curr Med Res Opin. 2011;27 Suppl 3:13-20.

18. Peyrot M, Rubin RR, Kruger DF, Travis LB. Correlates of insulin injection omission. Diabetes Care. 2010;33(2):240-245.

19. Jacobson D. Diabetes care and management: the patient's perspective. Paper presented at: American Association of Diabetes Educators 2011 Annual Meeting and Exhibition; Aug 2011; Las Vegas, NV.
20. Rosenfeld CR, Bohannon NJ, Bode B, et al. The V-Go ${ }^{\mathrm{TM}}$ insulin delivery device used in clinical practice: patient perception and retrospective analysis of glycemic control. Endocr Pract. 2012;18(5):660-667.

21. Quan H, Sundararajan V, Halfon P, et al. Coding algorithms for defining comorbidities in ICD-9-CM and ICD-10 administrative data. Med Care. 2005;43(11):1130-1139.

22. Hayward RS, Manning WG, Kaplan SH, Wagner EH, Greenfield S. Starting insulin therapy in patients with type 2 diabetes: effectiveness, complications, and resource utilization. JAMA. 1997;278(20): 1663-1669.

23. Nichols GA, Kimes TM, Harp JB, Kou TD, Brodovicz KG. Glycemic response and attainment of A1C goals following newly initiated insulin therapy for type 2 diabetes. Diabetes Care. 2012;35(3):495-497.

24. Wu N, Aagren M, Boulanger L, Friedman M, Wilkey K. Assessing achievement and maintenance of glycemic control by patients initiating basal insulin. Curr Med Res Opin. 2012;29(10):1647-1656.

25. Nichols GA, Glauber HS, Brown JB. Type 2 diabetes: incremental medical care costs during the 8 years preceding diagnosis. Diabetes Care. 2000;23(11):1654-1659.

26. Herman WH, Edelstein SL, Ratner RE, et al. Effectiveness and costeffectiveness of diabetes prevention among adherent participants. $\mathrm{Am}$ J Manag Care. 2013;19(3):194-202.

27. Herman WH. The economics of diabetes prevention. Med Clin North Am. 2011;95(2):373-384.

28. Diabetes Prevention Program Research Group. The 10-year cost-effectiveness of lifestyle intervention or metformin for diabetes prevention: an intent-to-treat analysis of the DPP/DPPOS. Diabetes Care. 2012;35(4):723-730.

29. The ORIGIN Trial Investigators. Basal insulin and cardiovascular and other outcomes in dysglycemia. N Engl J Med. 2012;267(4): 319-328.

30. Davis SN, Wei W, Garg S. Clinical impact of initiating insulin glargine therapy with disposable pen versus vial in patients with type 2 diabetes mellitus in a managed care setting. Endocr Pract. 2011;17(7): $845-852$. 


\section{Supplementary table}

Table SI Characteristics of patients with an average $\mathrm{HbA}_{\mathrm{Ic}}$ level $<7.0$ and $\geq 7.0$ in $201 \mathrm{I}$

\begin{tabular}{|c|c|c|}
\hline Average $\mathbf{H b A}_{\mathrm{lc}}$ level in \% & $\begin{array}{l}<7.0 \\
n=53,799\end{array}$ & $\begin{array}{l}\geq 7.0 \\
n=50,193\end{array}$ \\
\hline \multicolumn{3}{|l|}{ Region $^{\text {a }}$, n (\%) } \\
\hline Northeast & $5,429(10.1)$ & $4,948(9.9)$ \\
\hline Midwest & $|3,23|(24.6)$ & $11,879(23.7)$ \\
\hline South & $23,54 \mid(43.8)$ & $23,278(46.4)$ \\
\hline West & $6,054(I I .3)$ & $4,338(8.6)$ \\
\hline Unknown & $5,544(10.3)$ & $5,750(11.5)$ \\
\hline \multicolumn{3}{|l|}{ Antidiabetic Treatment, $\mathrm{n}(\%)^{\mathrm{b}}$} \\
\hline No prescription fills & $18,882(35.1)$ & $4,410(8.8)$ \\
\hline Oral antidiabetics & $32,035(59.6)$ & $35,920(71.6)$ \\
\hline Sulfonylureas & $7,789(14.5)$ & $16,246(32.4)$ \\
\hline Metformin & $22,285(41.4)$ & $23,504(46.8)$ \\
\hline Meglitinides & $532(1.0)$ & $838(1.7)$ \\
\hline Alpha-glucosidase inhibitors & $133(0.3)$ & $173(0.3)$ \\
\hline Dipeptidyl peptidase-4 inhibitors & $4,096(7.6)$ & $7,240(14.4)$ \\
\hline Insulin sensitizing agents & $4,831(9.0)$ & $6,464(12.9)$ \\
\hline Antidiabetic combinations & $4,859(9.0)$ & $7,683(15.3)$ \\
\hline Insulin & $5,692(10.6)$ & $22,205(44.2)$ \\
\hline Basal & $4,153(7.7)$ & $16,934(33.7)$ \\
\hline Pre-mix & $609(1.1)$ & $3,199(6.4)$ \\
\hline Regular & $278(0.5)$ & $\mathrm{I}, 035(2.1)$ \\
\hline Fast-acting & $3,020(5.6)$ & $11,833(23.6)$ \\
\hline
\end{tabular}

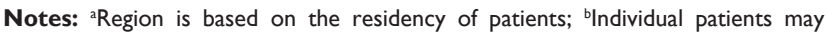
receive multiple treatment types.

Abbreviation: $\mathrm{Hb}_{\mathrm{lc}}$, hemoglobin $\mathrm{A}_{\mathrm{Ic}}$.

\section{Publish your work in this journal}

ClinicoEconomics \& Outcomes Research is an international, peerreviewed open-access journal focusing on Health Technology Assessment, Pharmacoeconomics and Outcomes Research in the areas of diagnosis, medical devices, and clinical, surgical and pharmacological intervention. The economic impact of health policy and health systems organization also constitute important areas of coverage. The manuscript management system is completely online and includes a very quick and fair peer-review system, which is all easy to use. Visit http://www.dovepress.com/testimonials.php to read real quotes from published authors. 